\title{
Déficit habitacional: um problema a ser resolvido ou uma lição a ser aprendida? ${ }^{1}$
}

\section{Denise Morado Nascimento}

Arquiteta, professora adjunta da Escola de Arquitetura da Universidade Federal de Minas Gerais (UFMG), Rua Paraíba, 697, Belo Horizonte, MG, Cep 30130-140, (31) 3409-8816, dmorado@arq.ufmg.br

\section{Raquel Carvalho de Queiroz Braga}

Arquiteta, pesquisadora voluntária do grupo de pesquisa Morar de Outras Maneiras da Escola de Arquitetura da Universidade Federal de Minas Gerais (UFMG), Rua Aimorés, 1239/1501, Belo Horizonte, MG, Cep 30140-071, (31) 3226-2216, raquelbraga@gmail.com

\section{Resumo}

O artigo trata da análise histórica e crítica da habitação social no Brasil, explicitando os primórdios que a transformaram num problema, expresso numericamente como déficit e acompanhado da perspectiva de uma solução. $\mathrm{O}$ objetivo aqui é expor criticamente a construção histórica do deficit habitacional em busca daquilo que the 'deu forma', evitando o entendimento de que o aumento de estoque de unidades de habitação, como o proposto pelo programa do governo federal Minha Casa, Minha Vida, seja solução à crise habitacional brasileira.

Palavras-chave: habitação social, revistas, deficit habitacional.

\footnotetext{
1 Este artigo é parte do resultado da pesquisa " $\mathrm{A}$ habitação social brasileira e as estruturas informacionais da arquitetura, urbanismo e engenharia", apoiada pelo PRPq/UFMG e pela Fapemig, desenvolvida pelas autoras no Departamento de Projetos da Escola de Arquitetura da Universidade Federal de Minas Gerais (EAUFMG)
}

\section{ntrodução}

Quando olhamos hoje as grandes cidades brasileiras nos deparamos com uma paisagem que abriga diversos modos de morar, explicitando desde condições econômicas privilegiadas até as mais miseráveis. Por um lado, o privilégio incorporado pelas estruturas urbanas formais; por outro, a pobreza manifesta nas ocupações informais. Entretanto, instituições públicas nacionais e internacionais reduzem esse antagonismo sócio-econômico, retratado espacialmente, a um problema nomeado déficit habitacional.

A Fundação João Pinheiro $(2005$, p.7) estima que o atual déficit esteja em torno de sete milhões de unidades, orientada por uma metodologia baseada em dois aspectos distintos: o quantitativo do déficit habitacional (dimensionamento do estoque de habitações) e a inadequação de moradias (especificidades internas desse estoque). A noção de déficit habitacional como número a ser quantitativamente superado cai por terra na medida em que há no país um estoque de seis milhões de domicílios vagos (FJP, 2005, p.31). Essa estatística revela não só a má distribuição das moradias, em razão da atuação dos agentes do mercado privado, mas também o baixo poder aquisitivo dos pobres no acesso ao estoque habitacional adequado.

As discussões trazidas neste artigo partem da premissa que é a nossa formação sócio-econômica que sustenta o modo de produção da moradia, visão essa que vai além dos métodos que embasam o número do déficit habitacional. Nosso intuito é 
reconhecer que as conexões e fronteiras históricas transformaram a habitação num problema, expresso numericamente como déficit e está sempre acompanhado da perspectiva de uma solução.

Tomamos como corpus empírico informações resultantes da pesquisa A habitação social brasileira e as estruturas informacionais da arquitetura, urbanismo e engenharia que tem como objetivo desenvolver uma interface gráfica, a partir de uma estrutura classificatória, que possibilite reunir e disseminar via web um mapa conceitual e temático da habitação social brasileira do século XX. As

2 Bolsistas do Programa de Aperfeiçoamento Discente (PAD) do Departamento de Projetos da EAUFMG - Alternativas para a Habitação Contemporânea, 2004, organizaram 33 periódicos de Arquitetura, Urbanismo e Engenharia, abrangendo o ano de 1920 ao ano de 2002. A organização destes periódicos foi feita por meio da categorização de artigos, textos, encartes e material publicitário, em sete assuntos principais: o uso do concreto, sistemas construtivos, economia e financiamentos, habitação, legislação e normatização, processos participativos, assuntos interessantes [ver http://www.mom.arq.ufmg. br/04_revistas/04rev_quadro. htm]. Na pesquisa A habitação social brasileira e as estruturas informacionais da arquitetura, urbanismo e engenharia, esses periódicos e seus artigos e/ou matérias foram reorganizados, em razão dos seus objetivos, resultando em 486 registros. Periódicos analisados: A Casa (1927 a 1941); ABA (1967); Acrópole (1939 a 1970); Arquiteto (1972 a 1978); Arquitetura \& Construção (1995 a 1998); Arquitetura e Engenharia (1946 a 1992); Arquitetura e Urbanismo (1939 a 1941); Arquitetura IAB (1963 a 1968); AU (1985 a 1999); Bem Estar (1958); Boletim do IAB/UnB (1981 e 1991); Brasil - Arquitetura Contemporânea (1953 a 1957); Brasília (1957 a 1965); Chão (1978 a 1980); Dirigente Construtor (1964 a 1971); Habitat (1951 a 1964); Módulo (1956 a 1987); Projeto (1979 a 1997); Sistemas Construtivos (1983 a 1988); Téchne (1992 a 1999). Mais informações: <http://www. mom.arq.ufmg.br/15_hs/ apresentacao.htm>. informações sobre habitação social foram levantadas em artigos de vinte periódicos brasileiros de arquitetura, urbanismo e engenharia, publicados entre 1920 e 1999, e em referências existentes no acervo da Biblioteca da Escola de Arquitetura e Urbanismo da UFMG que tratam da habitação no Brasil a partir de $1920 .^{2}$ Partimos do pressuposto de que a informação explicitada em periódicos e na literatura é parte da discussão acerca da maneira que a realidade é historicamente representada e construída. Acatamos a visão de Sundin (2003) sobre as revistas profissionais como uma das ferramentas que mediam normas e valores de uma comunidade; não apenas representam a realidade social, mas contribuem para estabelecê-la.

A interface foi construída a partir da Teoria da Classificação Facetada de Ranganathan que propõe a análise de um assunto por facetas, isto é, manifestações de certas características que obedecem a postulados pré-determinados. Os sistemas facetados podem ser construídos com o objetivo de organizar documentos e propiciar formas dinâmicas de acesso a estes. Nesse artigo, apresentamos os resultados referentes à análise da faceta déficit habitacional, representando um universo de 74 artigos, dentro de um total de 486. Mais do que definir os limites da problemática habitacional brasileira, acreditamos ser necessário expor criticamente a sua construção histórica em busca daquilo que 'deu forma' ao déficit habitacional.

Para tal, dividimos o periodo do século XX em quatro partes, cronologicamente aqui apresentadas: (1) "Os primórdios da problemática habitacional", ou seja, o início do século XX até os anos 1930, período reconhecido pelo crescimento das cidades, em razão do aumento do fluxo migratório de ex- escravos e migrantes, e pela escassez de moradias e serviços públicos; (2) "Período Vargas (1930-1945)", historicamente responsável pelas transformações das cidades brasileiras à mercê de uma política econômica de desestímulo à produção agrícola e de ações políticas direcionadas ao desenvolvimentismo do país em uma base industrial; (3) "Pós-guerra até 1964", período marcado pela forte determinação do mercado privado em responder pela demanda habitacional; e, por fim, (4) “Do BNH ao fim do século $X X "$ ", onde as bases das políticas públicas no enfrentamento do deficit habitacional, desde então presentes no cenário político brasileiro, comparecem.

Nosso ponto de vista ao analisar historicamente um assunto em busca da representação da realidade social atual é reforçado pelo entendimento de Marilena Chauí (2000, p.9) sobre o modo em que a realidade histórica brasileira é narrada. Para a autora, existe uma força persuasiva na representação desta realidade que permite legitimar soluções imaginárias para "tensões, conflitos e contradições", mas, que de fato, não se configuram como resolvidas no nível da realidade. O argumento de Chauí é um alerta para não julgarmos as presentes propostas de aumento de estoque de unidades de habitação, por exemplo, o programa do governo federal Minha Casa, Minha Vida, como possíveis soluções à crise habitacional brasileira.

A partir daí, o fio condutor deste artigo apóia-se na hipótese de que voltar-se às conexões e fronteiras históricas da habitação ao longo do século XX devem contribuir para um aprendizado sobre a realidade da problemática habitacional, configurando-se como contraponto da discussão já secular sobre a questão.

\section{Primórdios da problemática habitacional}

O crescimento das cidades acontece na medida em que o "desenvolvimento das forças produtivas é suficiente, no campo, para permitir que o produtor primário produza mais que o estritamente necessário à sua subsistência" (SINGER, 2002, p.9). Acatando o ponto de vista de Singer, entende-se que o crescimento das cidades é possível se a divisão do trabalho entre campo e cidade ocorre. Isso explica porque no Brasil, ao início do século XX, suas cidades 
apresentavam baixo grau de urbanização - grande parte da população vivia inserida em uma economia de subsistência, desintegrada de qualquer divisão supralocal (nacional ou internacional) de trabalho (SINGER, 2002). Entretanto, em razão da ampliação do fluxo migratório de ex-escravos e imigrantes frente ao aumento da produção das fazendas de propriedade da oligarquia nacional (café, cacau, açúcar, etc.), os serviços públicos (sistema viário, infra-estrutura, equipamentos de educação, saúde e habitação) começaram a atender cada vez mais precariamente as necessidades da população. A partir daí, o adensamento populacional das edificações existentes e o surgimento de construções provisórias erguidas pelos próprios migrantes em áreas ainda não ocupadas, de propriedade pública ou privada, passaram a ser notados nos centros de comércio regionais (Rio de Janeiro, São Paulo, Porto Alegre, Recife e Belo Horizonte).

Investidores privados, então, enfrentaram a premente demanda habitacional por meio da produção de alojamentos baratos para aluguel - hotel-cortiço, cortiço-pátio, casa de cômodos e cortiços, em sua maioria insalubres. A "constante valorização dos terrenos e a crescente angustia proveniente da falta de casas [...] havia de, forçosamente, fazer com que os capitalistas voltassem as vistas para esse gênero de negocio" ("As casas de villa", A Casa, 1928, n.55, p.17-19). Essa ação conferiu rentabilidade à atividade da construção, já que, em razão da demanda, a locação habitacional não apresentava riscos financeiros e o emprego do capital nessa atividade tornava-se vantajoso. A "terra assume feições de mercadoria no espaço urbano" das capitais (CARNEIRO, SOUZA, 2007, p.369).

Outra conseqüência do fluxo migratório foi a imposição pelo Estado burguês emergente de uma reorganização da vida social do migrante por meio da "medicina higiênica" (LEAL, 2007). Os migrantes, pobres, eram vistos como "multidões de desclassificados", "viciosos" e "avessos ao trabalho" (RIZZINI apud LEAL, 2007), e, sob esse ponto de vista, precisaram ser removidos do cenário urbano. Os alojamentos em comum eram considerados "verdadeiros focos de insalubridade e de corrupção physica e moral" ("As casas de villa", A Casa, 1928, n.55, p.17-19). Se por um lado, ações de limpeza física (demolição de casas coletivas, saneamento de portos, imunização de massa) aconteceram nos centros urbanos, por outro, sob o pretexto da insalubridade, ações de limpeza social (afastamento dos pobres das áreas centrais, campanhas educativas sobre novos costumes sociais, policiamento sanitário e isolamento de doentes) também ocorreram.

Ao abrigar o fluxo migratório, as comunidades foram caracterizadas como refúgio para "os desprovidos da sorte, os párias, os infelizes que não dispõem de recursos para desfructar vida melhor", conforme o artigo "As favellas vão desapparecer" (A Casa, 1927, n.44, p.17). Embora a crítica à demolição dos "infectos casebres, amontoados pelos morros" tenha comparecido nesse mesmo artigo, na medida em que promoveria o caminhamento da "elevada parcella de desabrigados" para a mesma "fileira dos que já vinham luctando contra a falta de moradia", a habitação foi, desde já, tratada como uma crise quantitativa. Para solucioná-la, bastaria a "construcção de pequenas casas hygienicas para abrigar enorme massa popular que está sendo deslocada desses morros", dando fim aos "antros".

Desde então, a habitação é apresentada publicamente como uma deficiência numérica que deve e pode ser mensurada e igualmente revertida. Àquela época, dois outros fatos reforçaram a noção de que construir casas em massa significava reduzir ou eliminar a demanda habitacional: em primeiro lugar, o governo Epitácio Pessoa (1919-1922), por meio do decreto n. 4029/1920, autorizou o Poder Executivo a construir habitações de aluguel para "operários e proletários" (ARRUDA, 2004); em segundo lugar, surgiu "a empresa construtora nacional" (FARAH, 1996, p.140), importante agente produtor de moradias comercializáveis.

Como resultado do higienismo e da produção de moradias centradas no valor de troca, inúmeras casas próprias de alvenaria, em sua maioria para a classe média paulista, foram construídas, promovendo o tijolo a "elemento símbolo do processo civilizatório deflagrado pelo dinheiro do café" (LEMOS, 2002, p.6). "Ícones românticos da arquitetura residencial européia, como o cottage, o bungalow e o chalet", forneceram o "modelo inspirador de um sem-número de paraísos proletários e vilas populares construídas pelo estado ou pelo empresário local" (LIRA, 2002, p.56). Em paralelo, planos de embelezamento e de melhoramento para as cidades foram executados, já 
transportando influências das diretrizes urbanísticas do movimento moderno em ascensão. No Rio de Janeiro, o plano Alfred Agache tratou a cidade como um organismo humano que, no decorrer de sua existência, apresenta doenças (matérias inservíveis e degradação) que precisam ser estetizadas (BERDOLAY, 2003). Em São Paulo, o plano Prestes Maia entendeu a cidade como conseqüência da iniciação da vida moderna, exigindo-se que cada lugar (ou zona) tivesse uma função estabelecida (habitação, recreação, circulação, indústria e trabalho). Em Belo Horizonte, a preocupação do governo foi com a "observância do plano original de uso e ocupação do espaço da capital", confinando a pobreza em áreas que implicassem no "menor transtorno possível" para o funcionamento da cidade administrativa (CARNEIRO, SOUZA, 2007, p.369). Nesse cenário, a cidade não mais é espaço de sociabilidade, mas de circulação (LEAL, 2007).

\section{Período Vargas, 1930-1945}

Por volta dos anos 1930, a cidade em diversos países latino-americanos, incluindo o Brasil, ainda era antiindustrial; ou, nas palavras de Singer (2002, p.116), a cidade era "bastião" dos interesses da oligarquia, consentida a "reter a propriedade do solo e as formas de exploração semi-servil da mãode-obra". O crescimento das maiores cidades era sustentado pelo fluxo migratório de ex-escravos e migrantes, o que acentuava as dificuldades de caráter urbano apontadas ao início do século - escassez de moradias e insuficiência de serviços públicos.

No entanto, o ponto de vista de Singer, aqui acatado, é que não devemos entender o crescimento da população como causa única do agravamento dos problemas urbanos nas cidades brasileiras, argumento este frequentemente encontrado na literatura para justificar o crescente déficit habitacional. Singer (2002) lembra bem que se quisermos analisar criticamente a evolução de uma cidade é preciso entender a relação entre o crescimento da sua população e a expansão da sua economia. Isso porque é em razão do desenvolvimento de novas atividades econômicas que a base urbana, necessária à sua prática, sofre transformações.

3 Ver mais em Bonduki, 1998.

É a partir do primeiro governo Vargas, que importantes passos em prol do desenvolvimento econômico foram dados, explicitando as transformações das cidades brasileiras. O primeiro deles foi a implantação de uma política econômica de desestímulo à produção agrícola; ao realizar tal política, o governo derrubou a oligarquia rural do poder e se aproximou dos interesses de outras classes sociais (classe média, tenentes e a burguesia agrária não-exportadora) (CARRARO, FONSECA, 2003). O segundo passo tratou da instauração de ações políticas direcionadas ao desenvolvimentismo do país em uma base não mais agroexportadora, mas, industrial.

As consequências do estímulo e do investimento na modernização do país foram não só a melhora do assalariado urbano mas, também, o aumento do fluxo migratório, desta vez sustentado pela massa rural em busca de emprego na economia industrial emergente. Se, por um lado, as atividades industriais e as políticas públicas desse período foram direcionadas ao operariado urbano, por outro, a agricultura tradicional foi empobrecida juntamente com os trabalhadores do campo. A moradia, então, passou a ser condição básica de reprodução da força de trabalho para que a industrialização pudesse ser assentada. Por isso, o governo deu início a uma fase de incentivo à produção intelectual em instituições públicas e privadas em busca de soluções para o crescente déficit habitacional, especialmente baseadas no aperfeiçoamento e na racionalização de processos produtivos.

Devemos lembrar os debates do I Congresso de Habitação, promovido pelo Instituto de Engenharia, em 1931 e a Jornada de Habitação Econômica, organizada pelo Instituto de Organização Racional do Trabalho, em 1941. Destacam-se ainda as pesquisas da Escola Livre de Sociologia e Política e da Subdivisão de Documentação Social da Secretaria de Cultura de São Paulo; os encontros organizados pelo Instituto de Arquitetos do Brasil (IAB); as matérias específicas de revistas especializadas como Digesto Econômico e Observador Econômico e Financeiro, Revista do Serviço Social, Sociologia, Boletim do Ministério do Trabalho, Indústria e Comércio, Revista do Arquivo Municipal, Revista Municipal de Engenharia, Arquitetura e Urbanismo do IAB, Arquitetura e Engenharia de Belo Horizonte, Habitat, Acrópole e Módulo, bem como reportagens publicadas pela imprensa diária. ${ }^{3}$

De uma maneira geral, os trabalhos apresentados trataram a habitação em três aspectos: (1) o técnico, 
demonstrado nas propostas de construções baratas e mínimas; (2) o higiênico, prescrito dentro da ordem sanitária vigente; e (3) o moral, considerado elemento fundamental na construção do país (SAMPAIO, 2002).

Uma das conferências dignas de atenção foi a do engenheiro Francisco Batista de Oliveira no Instituto de Engenharia de São Paulo, transcrita no artigo "A Casa Proletária Brasileira" (Acrópole, 1940, n.27, p.105.106 e 124). O palestrante explicitou a necessidade do entendimento numérico da crise habitacional, afirmando ser urgente o levantamento das "estatísticas honestas sobre a situação verdadeira da nossa massa popular" - elementos que pudessem conduzir a busca por uma "solução lógica e eficiente". Em seguida, Oliveira lembrou palavras do pensador Carlos Gide: "o alojamento é no solo condição necessária para o conforto, senão também para a saúde, e em certo modo, para a moralidade. [...] Tem certas virtudes elementares, como a limpeza e a decência, cuja prática é impossível num alojamento sórdido". E mais, sugeriu a quem desejasse "construir, reconstruir ou reformar um prédio [...] solicitar de um engenheiro ou arquiteto uma planta, onde as dimensões dos compartimentos sejam previstas e o destino das várias peças sejam de ante-mão prefixado".

Alicerçado por um "raciocínio" salvador do urbanismo moderno, Oliveira não fez nenhuma referência à expansão da economia urbana ou às condições sociais estruturais como pressupostos (ou elementos) para a análise dos problemas da habitação. Subjacente a este raciocínio, o tripé técnica-higiene-moral compareceu como garantia de qualidade espacial e social e como solução para o déficit habitacional, reforçando a ótica de determinados segmentos da sociedade: aqueles que precisavam evitar a invasão de terrenos (proprietários de terra), assegurar o "ambiente higiênico" (Estado), controlar a "expansão da cidade" (capitalistas) e proteger "valores humanos" (Igreja).

Durante o primeiro período do governo Vargas, as soluções para a habitação apresentadas por técnicos não passaram pela abordagem de questões como o aumento extraordinário do preço da terra urbana ou a ocupação das áreas beneficiadas pela infra-estrutura (transporte, água, esgoto e iluminação) por residências de luxo. Nem tão pouco em relação a partição da sociedade própria da política de seguridade social dos anos 1930: "de um lado, o segmento populacional com direito a ter direitos sociais, constituído pelas pessoas inscritas na economia formal, e o segmento composto pelas pessoas que não possuíam tais direitos, formado pela restante da população" (CARNEIRO, SOUZA, 2007, p.366). Ao contrário, as soluções higiênicoeconômicas significaram a resposta universalizada para a casa popular: uma aliança acrítica entre a racionalização da construção (máximo de aproveitamento de espaços úteis, mínimo de gastos, maior aproveitamento do terreno) e a reprodução de valores burgueses. Prova desse argumento é que as revistas, àquela época, passaram a publicar anúncios de fornecimento de cópias de projeto para casas proletárias ("Construcções proletarias", A Casa, 1935, n.131, p.37), pressupondo o entendimento do modo de morar dos operários urbanos.

Do ponto de vista teórico, os debates intelectuais e políticos da época acumularam argumentos em defesa da alteração de padrões técnicos e estéticos para viabilizar a nova 'moderna forma de morar', baseada na instauração de relações sociais utilitárias, na produção em série, na economia de área construída e de materiais, no uso de novas tecnologias (principalmente o concreto armado, solução ancorada pela pressão da indústria do cimento) e na uniformidade, racionalidade e funcionalidade dos projetos e da cidade. Os organizadores e participantes dos eventos citados "tendiam a perceber a cidade e a concebê-la numa visão 'limpa' de suas singularidades e sua história. Cidade 'moderna e racional', se reduzia, assim, a uma cidade harmoniosa, quantitativamente, nas plantas e cifras" (CORDEIRO, s.d). Em suas prescrições do modo de morar 'moderno', os pobres e operários eram ainda vistos como uma "grande multidão de trabalhadores e empregados" ou "massas populares" e descritos como indivíduos inferiores sem "cultura" e portadores de "vícios" (CARPINTÉRO, 1997, p.155) bem como "sob a categoria da consciência alienada" (CHAUÍ, 2000, p.27). Do ponto de vista prático, as propostas intelectuais e institucionais ao problema da habitação permitiram a estabilização financeira dos prestadores de serviços imobiliários, escritórios de arquitetura e engenharia e construtores, todos estreitamente relacionados com o principal interveniente na questão habitacional, o Estado. 


\section{Pós-guerra até 1964}

Em 1962, o Instituto de Arquitetos do Brasil/SP (IAB/ SP) produziu um documento afirmando ser necessário "construir 600.000 habitações por ano, para serem cobertas as necessidades brasileiras, por 30 anos" ("Problema da habitação no Brasil", Acrópole, 1962, n.278, Noticiário). Não só essa, mas também outras publicações revelaram, entretanto, que os dados sobre a questão habitacional eram, na realidade, imprecisos. Nos anos 1960, o déficit habitacional foi mensurado em 1,2 milhão ("Idéias e programas em favor da habitação econômica", Habitat, 1956, n.33, p.34-38), passando por 3 milhões de casas ("III Congresso Interamericano da Indústria de Construção", Arquitetura e Engenharia, 1962, n.64, p.41-42), 5 milhões de unidades ("Habitação popular", Arquitetura IAB, 1963, n.13, p.42-44), chegando até 6 ou 7 milhões ("Ainda a reforma habitacional", Arquitetura IAB, 1964, n.23, p.2). Não é difícil atestar que, metodologicamente, as estatísticas tenham sido falhas e incompletas: havia, de fato, uma grande dificuldade de se mensurar o número real da população atingida pela crise de moradias e como esse número se distribuía no território brasileiro.

Era certo, porém, a forte determinação do mercado privado (terrenos e imóveis urbanos) em responder pela demanda habitacional. Prova disso, foi o surgimento do incorporador imobiliário dos empreendimentos para venda: bancos e instituições de seguros bem como empresas ligadas às atividades da indústria, do comércio e da exportação agrícola. Aliada aos mecanismos da incorporação, a Lei do Condomínio (Lei 4.591/1964) também contribuiu para solidificar a presença do incorporador imobiliário na medida em que legalizou o desmembramento do terreno em frações ideais (VASCONCELOS, 2003). Ao incorporador foi consentido, juridicamente, não só desmembrar terrenos bem como criar o espaço vertical, promover o empreendimento e fabricar o solo (SAMPAIO, 2002, p.26).

Não por acaso, a resposta dada pelo incorporador ao mercado habitacional foi o espaço mínimo, ou a chamada kitnete, somada às áreas coletivas de serviços, de lazer e de comércio. Esses preceitos estabelecidos pelo mercado privado eram alinhados aos preceitos da produção habitacional pública - seriada, rápida, econômica e articulada com outras funções, além da 'morar'. "Evidente que para o projetista e para os investidores desses empreendimentos o que estava em jogo era a rentabilidade do capital por meio de uma obra a bom preço e a inserção no mercado de compra e venda que garantiria o retorno dos recursos empatados" (ROSSETTO, 2002, p.41).

Fica claro que o objetivo das iniciativas públicas não foi atender à demanda habitacional, mas sim "criar uma perspectiva de superação da problemática habitacional para contrapor às reivindicações trabalhistas [...] e contribuir para a expansão do setor de construção habitacional" (FARAH apud NOGUEIRA, 2005), além da maior geração de lucro. O próprio Instituto de Arquitetos do Brasil alertou que a solução para a crise habitacional não poderia depender "exclusivamente da iniciativa privada e da total ausência da ação estatal", porque os investidores particulares naturalmente agiam à base do lucro" ("O problema da habitação no Brasil", Arquitetura IAB, 1963, n.10, p.10-12).

Impulsionada pela garantia de uma mercadoria mínima vendável associada a outros itens igualmente vendáveis (lazer e comércio), a construção habitacional manteve sua referência como produto destinado aos moradores de alto poder aquisitivo: "o significativo número de habitações construídas tem se destinado quase exclusivamente às classes economicamente mais favorecidas", atestou o Seminário de Habitação e Reforma Urbana em Julho/1963 ("s.HRU", Arquitetura $I A B$, 1963, n.15, p.17-24). Em razão da incapacidade estatal de "obter-se, pela iniciativa privada, os recursos e investimentos necessários ao aumento da oferta de moradias de interesse social", o déficit de habitação se agravou ("s.HRU", Arquitetura IAB, 1963, n.15, p.17-24).

Claros equívocos permaneciam. Enquanto arquitetos, técnicos e setores públicos promoveram os princípios de economia, racionalidade, estandardização e a introdução de novos materiais e tipologias, as relações sócio-econômicas e a capacidade aquisitiva bem como os hábitos e práticas culturais dos trabalhadores foram ignorados. A solução habitacional foi reduzida ao espaço de morar genérico, repetitivo e mínimo (25 a 50 m2) em uma lógica de produção lucrativa para os investidores privados viabilizada pela simplificação, rapidez e barateamento dos processos de projeto e construção. A industrialização da construção 
caminhou lado a lado com a solução para o déficit habitacional. "Dificilmente [...] conseguirá algum govêrno acabar com o déficit de habitações. A não ser que através de uma política profundamente corajosa, que atinja a consciência coletiva, possa industrializar êsse setor" ("O conjunto habitacional de Cumbica", Acrópole, 1968, n.348, p.12).

O engenheiro civil Teodoro Rosso, que nos anos 1980 escreveu o livro "Racionalização da construção", evidenciou em 1962 a necessidade de reconsiderar os fundamentos da produção no campo da construção, "para imprimir-lhe um rumo completamente novo mediante a aplicação dos princípios próprios aos sistemas industriais" ("Um imperativo inadiável: a industrialização da construção", Acrópole, 1962, n.279, p.91-93;131133). Os argumentos de Rosso para a promoção da industrialização da construção foram justificados essencialmente por números referentes à produção habitacional e ao aumento populacional: "no nosso país, onde as fontes estatísticas mais categorizadas indicam um déficit atual de 3 milhões de residências, constroem-se cêrca de 100 mil casas por ano. Como consequência, houve por exemplo, no Estado da Guanabara um aumento de favelados de 300 mil em 1952 a um milhão e duzentos mil em 1960". Ao mesmo tempo, o autor fez uma forte crítica em relação ao modelo convencional da construção, classificado como "um artesanato mais ou menos primitivo, incapaz de dar uma contribuição eficaz e patente" à questão habitacional enfrentada em razão de seus índices de produtividade muito baixos. Mas ignorou que este modelo, por outras razões que não a valorização do capital, tenha sido historicamente referência para uma expressiva parcela de autoconstrutores e construtores diretos de moradias.

Também por meio do Seminário de Habitação e Reforma Urbana, o IAB/SP promoveu discussões sobre possíveis medidas para "corrigir o déficit de moradias e suprir a crescente demanda de habitações, serviços e equipamentos urbanos". O documento citou a adoção de "providências necessárias para o incremento da indústria de materiais de construção e desenvolvimento de processo tecnológicos, tendo em vista a padronização e estandardização dêsses materiais e a possibilidade de processos de préfabricação", mas ponderou a urgência em "melhorar as condições de habitabilidade de agrupamentos de subhabitações" (favelas, mocambos, malocas) e em "organizar as comunidades disciplinando e orientando tecnicamente as construções, com o aproveitamento também dos próprios recursos dos grupos sociais"; finalmente sugeriu ser necessário "tornar produtiva tôda a mão de obra ociosa local" ("s.HRU", Arquitetura IAB, 1963, n.15, p. 17-24).

Às vésperas da criação do Banco Nacional de Habitação (BNH), dois movimentos da produção habitacional se firmaram: a verticalização, legislada pelo Estado, e a periferização, preterida pelo Estado. O primeiro, vinculado às empresas de construção e aos incorporadores imobiliários - a produção planejada da moradia mínima, econômica e higiênica como solução técnica moderna; o segundo, conduzido pela ação direta dos trabalhadores despejados do mercado formal rentista e dos migrantes, em loteamentos periféricos vendidos a longo prazo (sem infraestrutura urbana) ou em terrenos clandestinos ou favelas (sem riscos de fiscalização) - a autoconstrução da casa própria.

\section{Do BNH ao fim do século $X X$}

Sustentado pelo entendimento das favelas como representantes de uma 'doença urbana' (que precisa ser exterminada) e pela pressão das classes dominantes preocupadas com a marginalidade urbana, o Banco Nacional de Habitação (Lei 4320, 21/08/1964) foi criado com o objetivo de "estimular a construção de habitações de interêsse social e o financiamento da casa própria, especialmente pelas classes da população de menor renda" ("Plano Nacional de Habitação" , Arquitetura IAB, 1965, n.36, p.37-40). Porém, o investimento financeiro do BNH foi acompanhado por incentivos dados às empresas privadas, o que as transformou em colaboradores na execução do plano habitacional. Essa, talvez, seja a principal razão para que o plano tenha se configurado como um dos eixos de sustentação da expansão do consumo da propriedade no Brasil (FARAH, 1996, p.173). A Programação Habitacional não alimentou "nenhuma pretensão de resolver a curto prazo o problema habitacional brasileiro. [...] os mecanismos institucionais existentes não comportariam a possibilidade de ultrapassar em curto prazo as metas apresentadas. [...] Ao Setor Privado caberá dessa forma a tarefa de contribuir para o atendimento da demanda restante" ("Plano 
habitacional decenal", Arquiteura IAB, 1967, n.59, p.14-16).

Para vencer o déficit habitacional da ordem de 7 a 8 milhões de residências, ainda que fosse ou um número estimado de "forma muito grosseira" ou "fruto da extrapolação de dados herdados de um passado longíquo" ("Estatísticas de construção", Dirigente Construtor, 1969, n.10, p.11), o BNH evocou a montagem de elementos pré-fabricados em série e a construção em larga escala. Entretanto, logo nos primeiros anos, o Plano Nacional de Habitação sofreu pesadas críticas. O IAB ("As favelas e a cidade", Arquitetura IAB, 1966, n.44, p.4) duramente denunciou que não seria mais admissível que se continuasse "a raciocinar em têrmos de apenas construir casas, e casas isoladas, numa tentativa vã de resolver a situação de uma população que vive em condições infra-humanas". A revista Dirigente Construtor ("Editorial", 1966, n.12, p.9) alertou: "trata-se também de um aspecto deplorável num plano que, por sua envergadura, poderia trazer notáveis contribuições ao problema sócio-econômico da habitação e que, no entanto, limitando-se aos caminhos clássicos, vai configurando apenas as favelas de um futuro próximo".

A preocupação com a racionalização e a mecanização de processos em atendimento à produção em massa, fomentadas pelo desejado desenvolvimento da indústria da construção, impediu que o Plano Nacional de Habitação incorporasse outros aspectos do modo de produção da moradia, como os sociais e econômicos. As possibilidades de se melhorar as condições do canteiro de obras, promover a autonomia dos usuários e desburocratizar os financiamentos foram depreciadas frente às metas de se aumentar o consumo da moradia e garantir o trabalho das empreiteiras. O BNH jamais tomou qualquer medida no sentido de organizar uma indústria da construção civil e aumentar a produtividade do setor para baixar os custos de produção da habitação em benefício dos moradores (BOLAFFl, 1979, p.69). Todas as decisões sobre a localização e a construção das habitações financiadas pelo BNH bem como suas operações e funções foram transmitidas para a iniciativa privada, garantindo rendimentos financeiros aos seus agentes.

Entre as 4,5 milhões de unidades habitacionais financiadas ao longo da existência do BNH (1964-1986), apenas 33,5\% foram formalmente destinadas aos setores populares (AZEVEDO apud FARAH, 1996, p. 175). "Nos 22 anos de existência do $\mathrm{BNH}, 92 \%$ dos recursos do Sistema Financeiro da Habitação (SFH) foram aplicados em benefício de famílias com rendimento superior a cinco salários mínimos, enquanto $80 \%$ da população brasileira ganha abaixo disso" ("Habitação popular: a distância entre a ação e a intenção", Projeto, 1988, n.110, p.151-153).

Sem surpresas, os programas habitacionais até então estabelecidos pelo poder público não reverteram a crise 'numérica' habitacional estabelecida desde o início do século. As revistas,da década de 80, apresentaram números sobre o deficit habitacional que vão de dez milhões de unidades ("Saída para a crise habitacional?", AU, 1987, n.11, p.81-84), passando por catorze milhões ("Habitação para os anos 90?", AU, 1990, n.33, p.58-77), até entre dez e quinze milhões ("A casa: um direito de vida", Módulo, 1982, n.70, p.20-27). Mas, raramente o déficit habitacional foi colocado como decorrência da "incapacidade do capitalismo brasileiro de produzir e comercializar a "mercadoria casa" para quem não tem renda, nem trabalho, nem tampouco liberdade política de se impor" ("Propostas do IAB/RJ - vinte anos depois", Projeto, 1985, n.75, p.81-83).

A habitação popular, assim denominada a partir do BNH, tornou-se sinômino do que havia de mais deplorável em termos de arquitetura e urbanismo: padronização dos projetos, conjuntos de grandes dimensões na franja periférica; execução precária; ausência de participação do usuário; financiamento inacessível às faixas de menor renda; casa própria como unica alternativa para o acesso à moradia" ("Habitação para os anos 90?", AU, 1990, n.33, p.58-77). "Transformamos o lugar em que vivemos (no sentido de repouso, lazer e convívio), a habitação, em um material avaliável, rentábil, capaz de se valorizar ou não, razão única de sua importância" ("Planejamento urbano e política habitacional", Arquiteto, 1975, n.24, p.9-10).

Nesse contexto, a autoconstrução e a chamada 'cidade informal' cresceram nas grandes metrópoles: em São Paulo, a população nas favelas aumentou 1000\% entre 1973 e 1987; 22\% do município vivia em moradias autoconstruídas (FARAH, 1996, p.209). "Para cada casinha resultante da ação oficial, surgiram outras quatro ignoradas, fora do 
esquema. Um milagre de eficiência? Não, apenas a ausência da monumental e esterilizadora máquina burocrática do governo" ("Está na hora de ver as cidades como são de verdade", Projeto, 1988, n.113, p.99-102).

Na tentativa de reverter as políticas públicas habitacionais em curso, o governo criou o Grupo de Trabalho de Reformulação do Sistema Financeiro de Habitação (GTR/SFH). O GTR/SFH sugeriu que a política habitacional incluísse ao provimento de moradia, soluções em conjunto de infraestrutura e transporte coletivo, em atendimento prioritário à população de até 3 salários mínimos; o financiamento das novas unidades poderia acontecer em soluções também de aluguel, comodato, leasing ou reforma, possibilitadas pela intervenção do Estado no setor de materiais de construção (FINEP, 1988, p.22). Entretanto, as medidas governamentais subsequentes feriram amplamente as recomendações do GTR/SFH. O BNH não só foi extinto, mas também transferiu suas operações e funções, patrimônio e estrutura administrativa para uma instituição bancária - a Caixa Econômica Federal, sem qualquer modificação na maneira de se conduzir a política habitacional. Permaneceu o "mesmo padrão perverso de financiamento, a mesma centralização decisória na esfera federal, e a mesma vulnerabilidade das agências governamentais aos interesses privados ligados à Construção Civil e à Promoção Imobiliária" bem como o uso clientelístico dos programas (FARIA, CASTRO, 1989, p.16).

Somente ao final da década de 80, a partir do momento em que os movimentos sociais (principalmente operários, mutuários do BNH, Movimento dos sem Teto) passaram a ser reconhecidos e a ter voz política, foi dado o passo na direção da invalidação das políticas públicas bem como do reconhecimento da autoconstrução e dos benefícios da participação do usuário nos processos de produção da moradia. Em entrevista à revista Arquiteto, Jorge Wilheim afirmou ser necessário "contar com a decisão do usuário e entregá-la a ele próprio, oferecendo contudo uma série de canais de auxílios que cada família poderia percorrer, de acordo com os seus problemas, para alcançar o modelo de habitação desejado" ("Wilheim: os diversos caminhos do plano habitacional", Arquiteto, 1975, n.26, p.8-9).
No caderno especial publicado pela revista Módulo ("O distanciamento da moradia popular", 1983, n.74, p.l), nove estudiosos do assunto criticaram a distorção no planejamento das cidades, por distribuírem conjuntos habitacionais em áreas onde não existia emprego. Nessas discussões, propostas de desapropriação de áreas subutilizadas e concentradoras de recursos e infra-estrutura próximas à área central da cidade para a construção de habitações populares foram feitas.

Outro importante debate, à época, diz respeito ao usucapião urbano, reivindicado pelos movimentos favelados. "Mais inteligente seria encarar de vez a necessidade de abrir o território urbano a ocupações previstas e planejadas. O governo aí teria importante papel: ofereceria os terrenos e daria subsídios técnicos para seu uso, além de coordenar a entrada de pessoas, construção de moradias e posterior evolução das condições urbanísticas e habitacionais. Invasões oficializadas, bem organizadas e projetadas, com suporte dos órgãos públicos." ("Está na hora de ver as cidades como são de verdade", Projeto, 1988, n.113, p.99-102).

Enfim, surgiram questionamentos sobre a insistente "atenção dedicada à análise numérica e metodológica da produção de habitações populares", apresentados, por exemplo, no artigo "A política habitacional como mecanismo de acumulação e legitimação" (Projeto, 1985, n.77, p.104-106). Os argumentos trazidos pelo arquiteto Pascoal Mário Costa Guglielmi demonstraram que "a política habitacional, refletindo a lógica desse Estado, longe de constituir-se num mecanismo de enfrentamento do problema de carência de moradias", foi "utilizada como implemento político a gerar renda e empregos no campo econômico pela articulação de medidas de cunho social. Dessa forma, os insucessos experimentados ao longo de seus vinte anos de existência [BNH] podem ser atribuídos ao fato de a produção habitacional não Ihe ser o objetivo final, mas o meio pelo qual se busca garantir os objetivos do Estado de garantir a acumulação (pelo carregamento de recursos ao setor privado da economia) e a legitimação (pela abordagem de uma questão popular central como a da casa própria)". Guglielmi explicita que os objetivos econômicos da política habitacional "sempre foram preponderantes [...] enquanto os sociais seriam complementares". 


\section{Finalizando....}

A história mostra-nos que não é mais possível sustentar o entendimento do deficit habitacional como resultado estatístico do reduzido ou do precário estoque de moradias versus o aumento populacional urbano. Informações publicizadas sobre a produção habitacional no século XX possibilita-nos afirmar que os mecanismos públicos e privados estabelecidos para o enfrentamento do déficit habitacional vem se ancorando: (1) na pré-determinação do modo de morar dos trabalhadores; (2) na mercantilização da casa própria; (3) no controle da expansão da cidade; (4) na racionalização do espaço mínimo; (5) na produtividade lucrativa da indústria da construção civil; e (6) na negação aos trabalhadores de baixa renda do acesso à terra, aos serviços urbanos e ao crédito.

Entretanto, a presença do déficit habitacional como tema de discussão parece estar garantida ainda por décadas na medida em que o reconhecimento e o aprendizado dos alicerces acima, além de suas repercussões nas atuais propostas públicas, não acontecem. O déficit habitacional ainda é visto como um problema numérico a ser superado pela provisão em massa de unidades habitacionais genéricas.

"Segundo um estudo da FGV Projetos elaborado para o SindusCon SP (Sindicato da Indústria da Construção Civil paulista) [...] o Brasil vai precisar de 27,7 milhões de novas moradias até 2020 para dar conta de atender o crescimento das famílias, zerar o atual déficit habitacional e acabar com cortiços e favelas. [...] O cálculo prevê eliminar as 2,431 milhões de moradias habitadas por duas ou mais familias e as 3,548 milhões de moradias inadequadas, como as favelas - segundo os últimos dados da PNAD (IBGE) de 2006" (FERNANDES, ROLLI, 2008).

Não por acaso, extensas críticas ao atual pacote habitacional do governo federal Minha Casa, Minha Vida tem sido feitas. O presente programa prevê a implementação do Plano Nacional de Habitação por meio da construção de um milhão de casas para famílias com renda de até 10 salários mínimos (SM):

\begin{tabular}{|c|c|}
\hline $\begin{array}{c}\text { Faixa de renda } \\
\text { familiar }\end{array}$ & $\begin{array}{c}\text { Número } \\
\text { de unidades }\end{array}$ \\
\hline 0 a 3 SM & 400 mil \\
\hline 3 a 4 SM & $200 \mathrm{mil}$ \\
\hline 4 a 5 SM & $100 \mathrm{mil}$ \\
\hline 5 a 6 SM & $100 \mathrm{mil}$ \\
\hline 6 a 10 SM & $200 \mathrm{mil}$ \\
\hline
\end{tabular}

Fonte:http://www.minhacasaminhavida.gov.br/

Para a operacionalização do programa Minha Casa, Minha Vida, no que diz respeito a faixa de 0 a 3 SM, o governo federal prevê a alocação de recursos pela União, com subsídio integral e isenção de seguro, e a prestação de no mínimo $R \$ 50,00$ com comprometimento de até $10 \%$ da renda familiar. Entretanto, repassa a tarefa da apresentação dos projetos às construtoras. Ora, ainda que a parceria com Estados, municípios, cooperativas e movimentos sociais esteja presente, a estrutura técnica necessária dos projetos em grande maioria dos municípios brasileiros é frágil, permitindo a transferência do processo de tomada de decisões (no que se refere aos aspectos técnicos, ambientais e de qualidade) ao setor da construção civil, com claros benefícios financeiros ao mesmo. Entre eles, o financiamento facilitado da cadeia produtiva, por meio do Banco Nacional de Desenvolvimento Econômico e Social (BNDES) para implantação, modernização e expansão de unidades industriais de casas pré-moldadas ou pré-fabricadas (bem aos moldes dos objetivos de industrialização dos meados do século XX).

Depois de ter vivido, entre 2007 e 2008, os melhores dias dos últimos dez anos e ter puxado o crescimento da economia, a construção civil volta a depender de políticas públicas. O pacote habitacional preparado pelo governo [...] é a única esperança do setor para reverter a desaceleração e expandir-se em tempos de crise (LIMA, 2009).

Além disso, a análise de projetos e a contratação de obras continuam a cargo de uma instituição financeira, a Caixa Econômica Federal. Ainda que o proposto plano seja uma oportunidade de minimizar o presente caos habitacional, construído historicamente no país, seria apropriado evitar as bases que lhe deram forma; senão, corremos o risco de colher os mesmos impactos negativos 
4 Fonte: http://www.minhacasaminhavida.gov.br/
5 http://video.globo com/Videos/Player/ Noticias/0,, GIM10046957823-UM+PANORAMA+D A+HABITACAO+POPULA $\mathrm{R}+\mathrm{EM}+\mathrm{LONDRES}+\mathrm{EUA}+\mathrm{E}$ +BRASIL,00.html da era BNH. Algumas perguntas de cunho básico continuam a ser feitas: "Evaniza Rodrigues, da União Nacional por Moradia Popular, diz que para alguns problemas centrais o pacote não propõe solução: "Onde as casas serão feitas? O que vamos fazer para segurar o preço da terra? Prefeitos que usarem as Zeis [Zonas Especiais de Interesse Social] terão prioridade?" (PAIVA, 2009).

Cientes dos aprendizados sobre a política habitacional brasileira, Raquel Rolnik e Kazuo Nakano (2009, p.4) afirmam que o pacote habitacional nasce "sobre uma política de ampliação do acesso ao crédito associada a distintas formas de desoneração da indústria da construção, sem conexão com qualquer estratégia urbanística ou fundiária, confundindo politica habitacional com política de geração de empregos na indústria da contrução". Longe, portanto, de ser uma política direcionada às famílias com renda entre 0 a 3 SM, representantes de 90,9\% do atual deficit habitacional brasileiro. ${ }^{4}$ Rolnik e Kazano (2009) asseguram ser mais acertado reciclar os edifícios vazios existentes em áreas com infraestrutura, possibilitar o regime das propriedades cooperativas, oferecer aluguel subsidiado, articular assistência técnica com recursos para a autogestão e compra de materiais de construção se quisermos buscar regulação territorial, ampliação do acesso à terra urbanizada e desenvolvimento social.

O arquiteto e professor Raymundo De Paschoal (2009) vai mais longe: o plano Minha Casa, Minha Vida é o "relançamento do financiamento público pelo governo federal sem nenhuma originalidade, pois existe há mais de 40 anos, com o chamado Sistema Financeiro da Habitação, implantado pelo regime militar. Um plano sem metas, sem etapas e sem aplicação quantitativa e qualitativa por regiões. Traz até uma "inovação" em planejamento: não tem prazo". A arquiteta Ermínia Maricato, em entrevista ao programa Sem Fronteiras, exibido pela GloboNews, afirma que, ao contrário, precisamos nos armar de uma "vontade férrea" para que a questão habitacional possa ser atacada, essencialmente, em duas frentes: (1) a aplicação do Estatuto da Cidade, no que se refere à função social da propriedade e à regularização fundiária e imobiliária; e (2) o aprendizado do setor privado, ainda retido por um produto de luxo, sobre a produção da habitação para pessoas de baixa renda. ${ }^{5}$
Parece ser inegável o reconhecimento de que os erros seculares em relação ao modo de se abordar o deficit habitacional no país continuam a ser cometidos, desvinculados que são de questões como urbanização, acesso à terra, gestão urbana e direito à cidade.

\section{Referências bibliográficas}

ABIKO, A. K. Introdução à gestão habitacional. São Paulo, EPUSP, 1995. Texto técnico da Escola Politécnica da USP, Departamento de Engenharia de Construção Civil, TT/PCC/12

ARRUDA, Ângelo. Nossas cidades: desafios habitacionais. In: SEMANA OFICIAL DE ENGENHARIA, ARQUITETURA E AGRONOMIA, 61., 2004, São Luis. Disponível em <http://fna.org.br> Acesso em Nov. 2007.

BERDOLAY, Vincente. Modernismo e espaço público: o Plano Agache do Rio de Janeiro. Revista Território, Rio de Janeiro, Ano VII, n. 11, 12 e 13, p.123-132, set./out., 2003.

BOLAFFI, Gabriel. Habitação e urbanismo: o problema e o falso problema. In: MARICATO, Ermínia (org.). A Produção Capitalista da Casa (e da Cidade) no Brasil Industrial. São Paulo: Alfa-Ômega, 1979. p.37-70.

BONDUKI, Nabil. Origens da habitação social no Brasil. $2^{\text {a }}$ ed. São Paulo: Estação Liberdade: FAPESP, 1998.

BRANDÃO, Arnaldo. Morar e viver: um estudo sobre a habitação das famílias pobres. Dissertação de Mestrado, UnB, Brasília, 1988.

CARNEIRO, Ricardo; SOUZA, José Moreira de. Moradia popular e política pública na região metropolitana de Belo Horizonte: revisitando a questão do déficit habitacional. In: FAHEL, M.; NEVES, J. A. B. (Org.). Gestão e avaliação de políticas sociais no Brasil. 1 ed. Belo Horizonte: PUC Minas, 2007, p.361-418.

CARPINTÉRO, Maria Varanda T. A construção de um sonho: os engenheiros-arquitetos e a formulação da política habitacional no Brasil. Campinas, SP: Editora da Unicamp, 1997.

CARRARO, André; FONSECA, Pedro Cezar Dutra. O desenvolvimento econômico no primeiro Governo de Vargas (1930-1945). In: CONGRESSO BRASILEIRO DE HISTÓRIA ECONÔMICA, 5, 2003, Caxambu. Anais eletrônicos.... Disponível em <http://www.abphe. org.br/congresso2003/Textos/Abphe_2003_53.pdf

CHAUÍ, Marilena. Brasil: mito fundador e sociedade autoritária. São Paulo: Ed. Fundação Perseu Abramo, 2000.

CORDEIRO, Simone Lucena. Moradia popular na cidade de São Paulo (1930-1940) - projetos e ambições. Disponível em http://www.historica.arquivoestado. sp.gov.br. Acesso em Nov. 2007.

DE PASCHOAL, Raymundo. Urbanista critica planejamento do pacote habitacional. PiniWeb, São Paulo, 11/05/2009. Disponível em http://www.piniweb. com.br/construcao/habitacao/urbanista-criticaplanejamento-do-pacote-habitacional-134521-1. asp. Acesso em Maio 2009. 
FARAH, Marta Ferreira Santos. Processo de trabalho na construção habitacional: tradição e mudança. São Paulo: Annablume, 1996.

FARIA, Vilmar E.; CASTRO, Maria Helena Guimarães de. Política social e consolidação democrática no Brasil (Cadernos n. 11). Campinas: NEPP/Unicamp, 1989.

FERNANDES, Fátima; ROLLI, Cláudia. País precisa de 27,7 mi de moradias até 2020. Folha de São Paulo, 25/02/2008. Disponível em http://www1.folha.uol. com.br/fsp/dinheiro/fi2502200802.htm. Acesso em Março 2009.

FIGUEIREDO, Geórgia Novis de. Industrialização e o espaço habitacional da arquitetura moderna em São Paulo (1930-1964). In: GITAHY, Maria Lucia Caira; PEREIRA, Paulo César Xavier. O complexo industrial da construção e a habitação econômica moderna 1930-1964.São Carlos: RiMa, 2002. p.36-51.

FINEP. Habitação popular: inventário da ação governamental 1984/86. Rio de Janeiro: FINEP, 1988, p.22

FSP - Folha de São Paulo. País precisa de 27,7 mi de moradias até 2020. 2009. Disponível em http://www1. folha.uol.com.br/fsp/dinheiro/fi2502200802.htm. Acesso em Março 2009.

FUNDAÇÃO JOÃO PINHEIRO/CENTRO DE ESTATÍSTICA E INFORMACÕ̃ES (FJP/CEI). Déficit habitacional no Brasil. 2.ed. Belo Horizonte: Fundação João Pinheiro/ Centro de Estatística e Informações, 2005

GITAHY, Maria Lucia Caira; PEREIRA, Paulo César Xavier. O complexo industrial da construção e a habitação econômica moderna 1930-1964. São Carlos: RiMa, 2002.

GITAHY, Maria Lucia Caira; PEREIRA, Paulo César Xavier. Arquitetura moderna e construção habitacional em São Paulo. In: O complexo industrial da construção e a habitação econômica moderna 19301964. São Carlos: RiMa, 2002. p.26-33.

HJØRLAND, Birger; ALBRECHTSEN, Hanne. Toward a new horizon in information science: domain-analysis. Journal of the American Society for Information Science, Maryland, v.46, n.6, p.400-425, Jul.1995.

LARCHER, José Valter Monteiro. Diretrizes visando a melhoria de projetos e soluções construtivas na expansão de habitações de interesse social. 2005. 189f. Dissertação (Mestrado em Construção Civil)Setor de Tecnologia da Universidade do Paraná, Curitiba, 2005. p.10

LEAL, Eduardo Martinelli. Da porta pra fora: a construção de um problema social. Pontourbe - Revista do Núcleo de Antropologia Urbana da USP, Ano 1, Versão 1.0, julho, 2007.

LEMOS, Carlos A. C. Prefácio. In: SAMPAIO, Maria Ruth Amaral de (org.). A promoção privada de habitação econômica e a arquitetura moderna 1930-1964. São Carlos: RiMa Editora, 2002. p.6-8.

LIMA, Samantha. Construção civil volta a depender do governo. Folha de São Paulo, São Paulo, 22/03/2009. Disponível em http://www1.folha.uol.com.br/fsp/dinheiro/fi2203200913.htm. Acesso em Março 2009.
LIRA, José Tavares Correia de Modernidade e economia do morar em Recife (1930-1964). In: SAMPAIO, Maria Ruth Amaral de (org.). A promoção privada de habitação econômica e a arquitetura moderna 1930-1964. São Carlos: RiMa Editora, 2002. p.52-76.

MARICATO, Ermínia (org.). A Produção Capitalista da Casa (e da Cidade) no Brasil Industrial. São Paulo: Alfa-Ômega, 1979.

MARQUES, Eduardo; SARAIVA, Camila. As políticas de habitação social, a segregação e as desigualdades sociais na cidade. In: MARQUES, Eduardo; TORRES, Haroldo (org). São Paulo: segregação, pobreza e desigualdades sociais. São Paulo: Ed. Senac São Paulo, 2005. p.267-296.

NOGUEIRA, Aída Pompeo. Arquitetura moderna e habitação social no Brasil: um abismo e algumas transposições. In: SEMINÁRIO DOCOMOMO BRASIL, 6. Niterói, 2005. Disponível em <http://www.docomomo.org.br>. Acesso em Nov. 2007

PAIVA, Natália. Pacote de Lula ignora aspectos urbanísticos. Folha de São Paulo, São Paulo, 22/03/2009. Disponível em http://www1.folha.uol.com.br/fsp/ dinheiro/fi2203200912.htm. Acesso em Março 2009.

ROLNIK, Raquel; NAKANO, Kazuo. As armadilhas do pacote habitacional. Le Monde Diplomatique, São Paulo, n. 20, p.4-5, mar. 2009.

ROSSETTO, Rossella. Arquitetura moderna e tipologias de mercado: uma primeira classificação. In: SAMPAIO, Maria Ruth Amaral de (org.). A promoção privada de habitação econômica e a arquitetura moderna 1930-1964. São Carlos: RiMa Editora, 2002. p.30-50.

SAMPAIO, Maria Ruth Amaral de (org.). A promoção privada de habitação econômica e a arquitetura moderna 1930-1964. In: Editora, 2002. p.14-28. São Carlos: RiMa

SANTOS, Milton. Metamorfoses do espaço habitado. 5. ed. São Paulo: Hucitec, 1988.

SINGER, Paul. Economia política da urbanização. São Paulo: Contexto, 2002.

SUNDIN, Olof. Towards an understanding of symbolic aspects of professional information: an analysis of the nursing knowledge domain. Knowledge Organization, v.30, n.3/4, p.170-181, 2003.

VASCONCELOS, Livius Barreto. O condomínio de casas e a incorporação para sua construção. Jus Navigandi, Teresina, ano 7, n.65, maio 2003. Disponível em: <http://jus2.uol.com.br/doutrina/texto. asp?id=4019>. Acesso em: 03 set. 2007.

WATANABE JR, Julio. Origens do empresariamento da construção civil em São Paulo. In: GITAHY, Maria Lucia Caira; PEREIRA, Paulo César Xavier. O complexo industrial da construção e a habitação econômica moderna 1930-1964.São Carlos: RiMa, 2002. p.54-69 


\title{
Housing deficit: a problem to be solved or a lesson to be learnt?
}

Denise Morado Nascimento, Raquel Carvalho de Queiroz Braga

\begin{abstract}
The article deals with the historical analysis and critique of social housing in Brazil, explaining the origins that transformed it into a problem, numerically expressed as a deficit and always into the prospect of a solution. The objective here is to critically present the historical construction of housing deficit in search of what formed it, avoiding the understanding that the increase of units stock of housing, as proposed by the government Minha casa, Minha Vida, is the solution to the Brazilian housing crisis.
\end{abstract}

Keywords: social housing, journals, housing deficit.

Déficit del hábitat urbano: ¿un problema a ser resuelto o una lección a ser aprendida?

Denise Morado Nascimento, Raquel Carvalho de Queiroz Braga

\section{Resumen}

El artículo trata del análisis histórico de la habitación social en Brasil, explicitando los fundamentos que la transformaron en un problema, expreso numéricamente como déficit y seguido de la perspectiva de una solución. El objetivo aquí es exponer, críticamente, la construcción histórica del déficit del hábitat urbano, en busca de lo que le "ha dado forma", evitando el entendimiento de que el aumento de la cantidad de unidades de viviendas, como el propuesto por el programa del gobierno federal:"Mi casa, mi vida", sea solución de la crisis de la habitación brasileña.

Palabras clave: habitación social, periódicos, déficit del hábitat. 